San Jose State University

SJSU ScholarWorks

Faculty Publications

Humanities

January 2004

\title{
Embodied Perceptual Practices: Towards an Embrained and Embodied Model of Mind for Use in Actor Training and Rehearsal
}

Shannon Rose Riley

San Jose State University, ShannonRose.Riley@sjsu.edu

Follow this and additional works at: https://scholarworks.sjsu.edu/humanities_pub

Part of the Arts and Humanities Commons

\section{Recommended Citation}

Shannon Rose Riley. "Embodied Perceptual Practices: Towards an Embrained and Embodied Model of Mind for Use in Actor Training and Rehearsal" Theatre Topics (2004): 445-471.

This Article is brought to you for free and open access by the Humanities at SJSU ScholarWorks. It has been accepted for inclusion in Faculty Publications by an authorized administrator of SJSU ScholarWorks. For more information, please contact scholarworks@sjsu.edu. 


\title{
Embodied Perceptual Practices: Towards an Embrained and Embodied Model of Mind for Use in Actor Training and Rehearsal
}

\author{
Shannon Rose Riley
}

\section{Theorizing Practice: The Mind/Body Problem in Performance}

Director: Choose an image that you have been working with and picture it as you move across the floor. Now, locate that image in a particular part of your body.

Actor: Should I see it with my mind's eye or try to feel it in my body? Should I see myself from the outside or the inside?

Director: Both; neither. What's your image?

Actor: A water bug.

Director: OK. Picture the bug-what does it look like? More importantly, what does it sound like? Move like? Imagine what the bug feels as it crouches near the ground and mimic that position. Now attempt to feel yourself turn into the water bug-starting at the tips of your antennae and moving down through your body. Feel your broad flat back as you move across the room. Feel your jointed legs carry your body. Where is your center of gravity? You exude the smell of a water bug. You see the world around you from the bug's perspective. What do you see?

This example of a conversation during rehearsal represents part of the problem of working with images and the body-although this phrase is already misleading. One is immediately caught in the language of the mind/body split, with its "Cartesian theatre"-Daniel Dennett's term for the model of the theatre in the mind (like the "mind's eye"), which displays mental images in detail. This image-screen of the mind represents a positivist Western metaphysics of mind over matter, brain over body, and intellectual transcendence over crude materiality. ${ }^{1}$ Within this model, the images on the screen, or in the mind, can directly affect the body, but rarely are affected by the body.

This parallels a similar problem in actor training since Diderot wrote his Le Paradoxe sur le comedien in $1830,{ }^{2}$ which theorized a split in the actor's consciousness:

It was Diderot's materialist analysis of the acting of his time which laid bare an essential paradox: that, whilst the actor appeared to be experiencing 
"real" feelings the opposite was more probably true. The good actor, in his view, was capable of mechanically reproducing these emotions in performance. Diderot suggested a dualistic model of the actor, the inner mind controlling the outer expression of feeling . . (Hodge 3-4)

The question of whether the character is created in the mind or in the body parallels the question of whether the image is located in the mind or in the body. The problem of whether the actor's emotion is motivated internally or externally parallels the question of whether the image is inside or out - they are caught in the same bind. Within the Cartesian model of the mind/body split it is nearly impossible to talk about different relationships between image, mind, and body, or to think of images as anything more than visual representations. Thus, in the West we often continue to describe visualization as a kind of mind over matter (Samuels and Samuels).

For example, over the last ten years I have used certain aspects of two contemporary movement forms-Authentic Movement (hereafter referred to as $\mathrm{AM}$ ) and Butoh-as a way of working with imagery in the development of my own performance work, as well as that of performance art students, visual artists, dancers, and actors. ${ }^{3}$ When trying to describe the way AM and Butoh each work with imagery, I have often found myself left with unsuitable metaphors and descriptions, such as "let the image emerge from your body rather than your mind," or "insert the image into your body and let the movement come from this place": or, perhaps worse, "become the ," or "be the ." Although my goal was to move beyond the mind/body split, my polarization of mind and body simply restated the split from the other direction-body over mind-and this was equally problematic.

In his introduction to Acting (Re)Considered, Phillip Zarrilli states that "[o]bjectivism and subjectivism remain two sides of the problematic, dualistic coin" (10). One side has tended to privilege either objective (external) methods of acting or character development, the second to reinscribe the binary through subjective (internal) methods. With dualism intact, either mind controls the body, or the bodymind becomes, according to Zarrilli, a kind of gestalt, claiming instantaneous expressivity (14). He goes on to note that much contemporary physical or movement-based performance training tends toward reinscribing the mind/body split from this latter perspective; the recent "resurrection of the body" in actor training has not been without problems:

If and when the body, experience per se, and/or "self" are reified as an essential "real," it problematically assumes that the subject or "self" is a stable location, and that a particular experience or transcendental self exists as an ideal or originary construct or essence. In some improvisational, bodily and/or experientially saturated approaches to acting where "being in the moment" is emphasized, a Cartesian dualism is simply reinscribed in the form of an overly simplistic and monolithic subjectivity often described as the actor's "presence," or as an "organic" or "natural" state of being. A reified subjectivist notion of "presence" is as complicit in a dualist metaphysics as is the Cartesian "mind." Neither provides an adequate account of the "body" in the mind, the "mind" in the body, or of the process by which the signs read as "presence" are a discursive construct. (15) 
Much of the application of Butoh and AM to actor training has persisted in this kind of rhetoric of presence and the reinscription of the mind/body split. For example, movement coach Judith Koltai, a pioneer in using AM for actor training, particularly in the development of voice and text, speaks of "transforming consciousness" and describes AM as a "natural" and "fertile" ground for the "essential processes of the actor's art" ("Forms" 47). She describes the "rendering of inner experience into visible form through the medium of the body . . . [as] the defining base of both Authentic Movement and the art of acting" (48). Similarly, performer Andrea J. Olsen speaks of "the unconscious speaking directly through the body" in the Authentic Movement process (Olsen 48). These investigations into the use of AM for the development of performance work and in actor training are very important, yet remain modeled on the kind of bodymind gestalt described above, complete with claims about AM's ability to unlock deep truths from the body. And while AM is certainly helpful in a therapeutic context, much of the theory that describes the process in this way is not particularly helpful in actor training or performance. The form's usefulness in actor training can be fully explored only if the theoretical and practical language is reconsidered, reframed and applied differently.

One might assume that Butoh, a Japanese movement form, is already based on a model of mind and body that is different from the Cartesian split-that perhaps Butoh is outside a conversation on Diderot's paradox. Even if this were true (more on this later), Butoh is also taught in the US, Australia, and Europe, often for Western students if not by Western dancers/teachers. As soon as this translation of practice is made, Butoh often becomes mired in the same problem of language that troubles AM and other visualization processes. As Zarrilli notes, mind/body dualism tends to be resilient (13). Further, writing by Japanese authors on Butoh (either written in English or translated) seems to reinscribe a version of the mind/body split: "By practicing the exercises repeatedly, dancers learn to manipulate their own bodies physiologically and psychologically. As a result, butoh [sic] dancers can transform themselves into everything from a wet rug to a sky and can even embody the universe, theoretically speaking" (Kurihara 16). Not only is there a clear split between a controlling psychology and a manipulable body, but there is also a heroic quality, even virtuosity, projected onto the Butoh performer. ${ }^{4}$

With these interconnected problems in mind I began to explore Authentic Movement and Butoh through the work of neurologist Antonio Damasio and linguist Mikhail Bakhtin. My goal was to find a way to talk about, and ultimately explore, the use of imagery, movement, and perception in performance training and rehearsal without having to resort to discourses that reinscribe the mind/ body split and its positivist metaphysics. On one hand, I felt limited by the uncritical acceptance of the body as an originary source of knowledge in much of the language of Butoh and AM. On the other hand, critiques like the one outlined by Zarrilli above, although extremely useful, may leave the actor confused as to where to begin to develop a character. It is true that actors today can rely less and less on the subjective/objective dichotomy in developing performance work; and if we are to take seriously recent theories of the subject, and are to prepare actors to perform in contemporary works, like Wallace Shawn's The Fever, which tend to defy more traditional acting approaches (such as looking for the character's objective, or the "action" in a section of the text), we need to rearticulate useful practices and new theories. 
I suggest that a contemporary theory of acting must acknowledge the recent critique of the subject in its various formations, but must also help the performer navigate what might be called a mediated liveness, or a provisional sense of presence that has more to do with perception and attention than with any essential trait or quality. In other words, a practice and theory of acting must account for the actor's "live body" - no matter how mediated (culturally, electronically, etc.) that body, identity, etc., might be. There must be a way to hold onto a provisional notion of presence as a tool for the actor. Not the presence of positivist metaphysics with its myth of an essential unified self and its "belief in unmediated communication" (the possibility of pure self-expression) (Lutterbie 21), but a presence constituted in the moment by means of attention to the processes of the organism and its relationship with its environment. Embodied perception offers such a practice.

In the model of Cartesian theatre, visualization and acting are seen as the result of mind over body, or in the manner of Zarrilli's bodymind gestalt, reversed to body-over-mind. What is required is a language and a model of mind in order to talk about visualization techniques and the relationship between brain, body, and mind without reinscribing the mind/body or inner/outer paradigms. Damasio and Bakhtin provide models of mind and language that allow us to recuperate the visualization methods of AM and Butoh as a theory of embodied perceptual practices. Reading AM and Butoh through Damasio and Bakhtin permits me to discuss principles similar to those discussed by Grotowski or Barba, i.e., the via negativa, without needing to reinscribe a mind/body split or engage in the metaphysics of presence. What is unique in the approach outlined in this essay is the further development of the application of Damasio's model of mind to analyses of actor training, ${ }^{5}$ and the re-articulation of visualization techniques in $\mathrm{AM}$ and Butoh as embodied perceptual practices in order to offer a combined approach to actor training that teases out various pathways for working with fully sensual imagery.

In order to accomplish this reframing of visualization from the model of Cartesian theatre into one of embodied perceptual practices, I will first take the reader through a quick account of AM and Butoh, followed by a summary of the principles of Damasio's model of mind and the importance of Bakhtin for our investigation. After this quick introduction to the necessary theory, I will offer a modified definition of visualization-as embodied perceptual practices-and will contextualize this approach within contemporary actor training. My claim is that what I will outline as embodied perceptual practices offer the actor a means to develop an ability to think and problem-solve with his/her entire organism, and an increase in the ability to hold simultaneous attention on various layers of perception, from a fine-tuning of attention to various psychophysical processes, to perception of one's being-in-relationship with others and the environment. This creates a state of what I will describe as perceptual polyphony that allows both expansion and clarity of focus for the actor. In the model of embodied perceptual practices, the visualization processes culled from AM and Butoh function as a combined movement practice (in combinations of varying degrees) for clearing the actor's body of cultural and personal movement and embodiment patterns, ${ }^{6}$ for sourcing the character and the text in the creative process, and for scoring the text for performance.

To achieve this goal, this paper establishes the following framework: 1) neurologist Antonio Damasio's model of mind, read through Russian linguist 
Mikhail Bakhtin's notions of the dialogical and the polyphonic, provides a helpful metaphoric model to move beyond the reproduction of the mind/body split; 2 ) Damasio/Bakhtin provide a theoretical language in order to reframe much of the discourse on actor training and to retrieve Butoh, and particularly AM, from the discourse of presence; 3) within this revised model, certain aspects of AM and Butoh offer embodied perceptual practices that can be used to attune the actor to the process of his/her embrained and embodied mind, as well as for sourcing and developing a performance; and finally, 4) a practical application of this approach is applied to two recent productions of Wallace Shawn's The Fever.

\section{Imagery and the Body in Authentic Movement and Butoh}

Authentic Movement is a form of relational movement therapy based on a psychoanalytic model of mind. Originally referred to as Movement-in-depth by Mary Starks Whitehouse, a modern dancer and Jungian analyst working during the 1950s-'70s, it was later named Authentic Movement by her student Janet Adler, based on Whitehouse's use of the phrase (Adler, "Witness" 146). Adler began working with Whitehouse in 1969, and in 1981 founded the Mary Starks Whitehouse Institute, the first place to teach AM. The first usage of the term authentic movement is attributed to the critic John Martin in a review of Mary Wigman's dance from 1933 (J. Adler, Offering xv).

When practicing Authentic Movement in its basic form, or dyad model, there is one mover and one witness. The mover moves with her eyes closed while the witness sits to the side and offers his attention. The mover's eyes are closed in order to bring the mover's attention to her other senses and into a more perceptive state of awareness. However, the mover should open her eyes so that they are softly-focused before making any rapid or large-scale movements in the space. ${ }^{7}$ The mover moves in any way she chooses for a designated period of time-she should not be concerned with how the movement looks, but rather how it feels (another reason for closing the eyes). The mover may make sounds, interact with objects or others in the space; the movement may be very small or very large and active. There are no rules other than that the mover chooses to follow an impulse, or to let it go and follow another with as much awareness as possible. At the end of the movement period the mover and witness usually process verbally; in the more therapeutic model of AM the mover usually speaks first, sharing whatever she chooses; the witness shares if acceptable to the mover. Everything the witness shares is about his own experience, not a projection onto the mover of the witness's interpretation.

Authentic Movement attempts to activate what Jung called the "active imagination," a kind of internal "film" being "unrolled inside" in the manner of Cartesian theatre, depicting "unconscious" material (G. Adler, Studies in Analytical Psychology, qtd. in Frantz 20). The body in this sense is a kind of deep container as it gives up what are often described as the memories of trauma, or more problematically as images from the "collective unconscious" (reflecting the Jungian bias of AM). Because AM was developed as a form of movement therapy, and is practiced as such today, much of the writing on the subject is from a clinical or psychoanalytical perspective and clearly reinscribes the kind of subjective presence that Zarrilli problematizes. For example, Janet Adler notes that "presence allows offerings to emerge from the body as a vessel" (Offering 150). 
Butoh, a contemporary form of Japanese dance, is difficult to describe because of the many forms and manifestations that have emerged internationally over the last forty-five years. It is generally accepted as the product of both the collaborative and personal investigations of Kazuo Ohno and Tatsumi Hijikata during 1950s postwar Japan, crystallizing with Hijikata's 1959 performance of Kinjiki (Forbidden Colors), based on the novel by Yukio Mishima (Klein 1). In 1961, Hijikata named the movement retroeffectively as Ankoku Butoh-ha. According to Klein, the term ankoku means "pitch black," butoh translates as "dance-step," and ha as "group or party," as in a political party (2). Thus, Ankoku Butoh-ha is a complex signifier, often translated as the "Dance of Utter Darkness," although this translation seems to omit the meaning of the character ha. It must also be noted that before Hijikata's phrase, butoh was used to refer to all Westernstyle dance, including the flamenco, ballet, etc. Ankoku Butoh-ha refers not only to the original group of dancers that worked with and around Hijikata, which disbanded in 1966, but also to the general movement, which retained the name. In the 1970s the movement became increasingly referred to simply as Butoh, and since then "has come to signify the entire spectrum of dance that has, in one way or another, been influenced by Ohno Kazuo and Hijikata Tatsumi" (Klein 2). As Klein notes:

Not only do the large number of people influenced by the movement and the wide range of styles that have evolved from it conspire against coming up with an all-inclusive definition; but the philosophy of Buto [sic] itself is vehemently opposed to any critical interpretation that might limit the possible meanings evoked in the viewer. (2-3)

According to Nanako Kurihara, it is naive to think of Butoh as being purely Japanese (thus necessarily grounded in Eastern concepts of mind and body), because Hijikata's Butoh was already the result of various intercultural transmissions (17). Hijikata also makes reference to Herbert Marcuse, Georges Bataille, and Jean Genet ("To Prison"), and presents an unclear, if somewhat problematical, relationship between mind and body. For example, Hijikata gives a list of images in order to convey exercises as a "condition for forming a mere body" ("On Material" 6; emphasis added). To say that the Butoh dancer attempts to form a "mere body" or only a body, in order to bypass a culturally-constructed brain which limits that body, is nonetheless to form a concept of a body at odds-caught up in the kind of bodymind gestalt described above. There also seems to be a discourse of individual presence in Hijikata's writings, and certainly in his own mythic construction of personality: “. . . I think individuality is important. Individuality is the overflow to the outside" ("Plucking" 54). Nanako Kurihara goes so far as to say that Hijikata "presented something only a live body can express. That is the essence of Hijikata's butoh . . . this body only comes alive when it is chased in to [sic] a corner by words and pain-that is, consciousness" (16). This sounds close to Authentic Movement and its discourse of authentic presence and body as consciousness (J. Adler, Offering).

In practice, Butoh and AM share many similarities, including a focus on breath, the use of improvisation, and particularly, working with imagery and movement. Neither form uses a mirror in the tradition of teaching Western dance; each is more concerned with the feel, or perception of the movement rather than what the dance "looks like." (Several of these similarities may be traced, at least partially, by way of Mary Wigman, a German dancer who focused on improvisation and the use of guided imagery in training dancers. ${ }^{8}$ ) However, 
Klein notes, "for any one technique practiced by a particular Buto [sic] group, it is always possible to find another group that rejects it, or who may have developed some other technique that has a completely opposite goal" (26). Nonetheless, working with imagery is widely used: "the process of imaging for both the dancer and the audience is at the aesthetic core of Butoh" (Fraleigh 142).

Authentic Movement and Butoh each explores relationships between imagery and movement, yet differ in terms of the technique. For example, in improvisational Butoh ${ }^{9}$ there is intention in choosing the initial image; one works with an image, eyes usually open but softly focused, in order to initiate the movement: "in the free atmosphere of Hijikata's studio, we would translate images into pure movement" (Yukio Waguri, qtd. in Blackwood). In AM, one works in stillness, eyes closed, in order to attend to emerging movements/images. The movement initiates the image as the mover waits in silence: "there is an ability to stand the inner tension until the next image moves them" (Whitehouse, qtd. in Frantz 22; emphasis added). Whitehouse was interested in "images that come out of the movement experience," encouraging her students to "allow themselves ... . to 'be danced by' a compelling inner image" (Chodorow 283). Simply, in Butoh the image initiates the movement-one achieves metamorphosis via movement; in AM the movement initiates the image-moving from stillness, images emerge. But again, language fails us. We are close here to re-positing both sides of Zarrilli's coin: Butoh seems perilously close to mind-over-body visualization and AM to bodymind gestalt. As a result of the Cartesian split there is a sequencing problem in my description: which comes first, image or movement? Which initiates-body or mind? Certainly this process is more simultaneous than linear: Damasio's model gives us a way to discuss and use these different imaging processes without falling into this dilemma. Said again, the metaphors that describe either an imaging mind-which translates images into a receptive body-or a bodily depth that gives up images as if by floating them to the surface, to be retrieved by the knowing mind, are equally problematic. Each maintains mind/body dualism. We need to find a way to use AM and Butoh in actor training contexts without resorting to the language of depths and surfaces, insides and outsides. By taking a discussion of visualization in Authentic Movement and Butoh out of the discourses of psychology and the metaphysics of presence, and into the discourse of contemporary neuroscience, we begin to find such a language.

\section{Damasio's Theory of Mind and Bakhtin's Concept of Dialogical Relations}

Neurologist Antonio Damasio postulates that what we mistakenly call "the mind," as if it were an object located in the brain, is more accurately an interactive relational process between brain, body, and environment. Specifically, the process of mind is constituted by what he calls "multiple, parallel, converging streams," coded as images, which flow throughout body and brain in response to the environment, forming multiple temporary "feed-forward and feed-back projections ...." (Descartes' Error 93). For Damasio, these images constitute what we commonly refer to as thought. Mind is "embodied, in the full sense of the term, not just embrained" (118), and images are "the currency of our minds" (Feeling 319). It is important to distinguish that for Damasio, an image is more than a 


\section{Shannon Rose Riley}

visual representation; it is a "pattern in any of the sensory modalities, e.g., a sound image, a tactile image, the image of a state of well being" (9). Thus, in Damasio's schema, the "brain and the rest of the body constitute an indissociable organism"; this organism "interacts with the environment as an ensemble"; what we call mind is the result of this process; and what we call environment is in part a result of the organism's activity as well as its matrix of activity (Descartes' Error xvi-xvii). Environment here is meant to refer to the organism's immediate physical surroundings; it includes climate, space, and any proximate objects, organisms, etc. Environment influences, and is influenced by, the organism. Finally, it is important to note that within the organism, Damasio outlines "two principal routes of interconnection" between brain and body-the nervous system and the bloodstream (87). Information, as imagery, moves along these paths, exchanging neural and chemical signals at various sites.

Mikhail Bakhtin's concept of dialogue as polyphony, developed in terms of the novel, serves as a critical overlay to Damasio's theories. Polyphony implies that the dialogue is not neat and tidy (e.g., first brain speaks, then body responds); it is not always translatable, resolvable. There are interruptions, incomplete thoughts, and urgent responses. Polyphony indicates that more than one voice may speak at a time; they may disagree. Bakhtin's notion of dialogue does not simply consist of two "rejoinders" or "partners in dialogue" (72), but is already multivoiced, or polyphonic-made up of more than two voices. Bakhtin speaks of "dialogic overtones" (92), and "dialogical interrelations" (93), allowing for a complex interactive network of various types of communication which are similar to Damasio's "multiple converging streams" and "feed-forward/feed-back projections." Overlaying Bakhtin's notion of multiple rejoinders in shifting context with Damasio's similar structure of brain/body/environment provides a metaphoric model of embrained/embodied mind that is culturally contextualized, engaging multiple receptors in the process of imaging-not just brain and body represented as a rigid structural dichotomy, but a polyphony of receptors (as rejoinders) throughout the organism and environment. This kind of system of communication makes it difficult for any one voice to control the others, or to limit the conversation to a simple binary as in the Cartesian model of mind/body dualism.

\section{What's in an Image?}

One might argue that images are the currency of our minds. -Antonio Damasio, The Feeling of What Happens

Damasio's definition of an image contains two major premises: 1) images are more than visual representations, including textural, aural, olfactory images, etc., and 2) images are neither static, cohesive structures, nor are they located discretely in the brain; all images are emerging and embodied. Images are more than what we incorrectly refer to as mental representations of a visual nature; they are fully embodied and embrained representations generated in response to data from any of the senses or internal organs (Feeling 318). Damasio distinguishes between two kinds of images: "perceptual images," formed through the act of perceiving in the moment; and "recalled images" that include memory images, like the smell of baking bread, and images we've more or less invented, i.e., an alien from outer space (Descartes' Error 96-97). We generate perceptual images, or "on-line dynamic body maps" (152) in the moment, in response to 
data from various receptors. Perceptual images are formed from three sourcesthese include the perception of touch and the movement of muscles and joints, called proprioception; the perception of the state of the organs and viscera, or interoception; and the perception of one's relationship to their environment, or exteroception. Recalled images are formed from stored neural patterns, or memory, and can be formed intentionally or triggered in response to other perceptual or recalled images.

These definitions are a way to rearticulate the process of visualization in $\mathrm{AM}$ and Butoh. For example, instead of speaking about locating an image in a particular part of the body, we can speak of working with recalled and perceptual imagery, being sure to focus attention on all three kinds of perceptual imageryproprioceptive, interoceptive, and exteroceptive-and the polyphonic relationships between them. Focusing on a description of recalled and perceptual imagery and associated feelings, as opposed to more abstract discussions of metamorphosis, or the body as a vessel, provides a way to talk about visualization in AM and Butoh that is more effective in performance training and less caught up in the discourse of the mind/body split and the metaphysics of presence.

In the Damasio/Bakhtin model, visualization is the conscious process of working with these various kinds of fully sensual images, layering recalled imagery, perceptual imagery, and associated feelings in a state of perceptual polyphony. In this revised model, Cartesian visualization techniques can be seen as focusing exclusively on recalled images of a purely visual nature, as indicated by the outmoded metaphor of holding a picture in the mind's eye, ignoring perceptual imagery altogether. Embodied perception is a better way to refer to our revised approach, and it focuses on layering recalled imagery of a fully sensual nature (aural, textual, visual, etc.) with perceptual imagery as it unfolds in the moment.

Damasio's somatic marker hypothesis is also helpful in reframing the language of AM and Butoh, and proved particularly useful in the rehearsal process. In this hypothesis he attempts to describe how a body-state, a feeling, and an image become connected, creating a type of embodied memory imprint. Somatic markers are neurological patterns which link a particular recalled image(s) with particular perceptual images, and a particular body feeling. The best example Damasio offers is that of experiencing an "unpleasant gut feeling" when considering a future negative outcome (Descartes' Error 173). Significantly, somatic markers are not static but become re-marked, re-imagined with every re-collection. Thus, what we define as an image is not so much in the brain-in the model of Cartesian theatre-as it is constituted throughout the organism in various feed-forward and feed-back loops based variously on intention, perception, and current or remembered body states.

\section{Authentic Movement, Butoh, and Embodied Perception}

If, according to Damasio, all images are already embodied, and mind is already the process of brain, body, and environment meeting in the flow of an image, what is it that embodied perceptual techniques are doing? All images may be physiologically embodied, but in a culture that has thought of images as a kind of property of the brain for so long, we have forgotten how to visualize using all of our senses. Certainly most visualization techniques do not offer an embodied approach, because they only focus on working with recalled imagery 


\section{Shannon Rose Riley}

of a visual nature, and remain mired in dualist terminology. In what is more clearly described as embodied perception, recalled images are attentively juxtaposed in a dialogue with the three kinds of perceptual images. Embodied perceptual practices include a focus on breath and perceptual imagery as the primary means of bringing attention to the dialogue between perceptual and recalled images, which are fully sensual in form. It is particularly through the breath that embodied perceptual techniques attempt to merge image, movement, and text in ways that are palpable. Embodied perception, put simply, is working with fully sensual imagery using one's breath and all of one's senses.

But how does this model help us solve our problem with describing visualization in Butoh and Authentic Movement: Does the image start in the body or in the mind? Inside or out? Before or as a result of movement? Most clearly, in our revised model, these become the wrong questions. Instead of having to suggest that you choose an image and move from it, or insert it into your body, I can suggest that you begin with a recalled image, then bring attention to the three levels of perceptual imagery-in other words, check on your interoceptive sensations (breath, heartbeat, organs), your physical sensations of movement (muscles, joints, bones), and your sensation of environment (other people, location, warmth, etc.). In an AM session I no longer need to say, "Let the image emerge from your body, or let the image emerge from the movement," but can suggest that the student begin by tracking the three kinds of perceptual imagery, then adding attention to fully sensual recalled images as they occur, following or releasing them by choice. This process is much more accurate and detailed in developing actor awareness and collecting specific information during rehearsal; it is also minimizes the problem of allowing mind, body, brain, or any other such concept to take control of the image pathway. In this model all of the mind systems-brain, body, and environment-are engaged in perceiving the recalled and perceptual imagery.

Interestingly, the paradox that Diderot read into the actor's awareness can be resolved using Damasio's model of mind and a theory and practice of embodied perception, wherein the actor is aware of her organism in space, her breath, her interoceptive, exteroceptive, and proprioceptive information, while she is simultaneously aware of the various recalled images that constitute the role she is performing-the rehearsals, the text, images, etc. The intentional process of layering perceptual images with the recalled images-which constitute the role or performance-creates a model wherein there is no paradox between the actor's attention and so-called presence. In this model attention is not split so much as layered and in a state of ongoing dialogue and change. In our revised terms, then, embodied perceptual processes focus on becoming attentive to recalled images and their dialogical relationship with perceptual imagery, offering the actor a method for becoming attuned to the polyphonic connections between body and brain, organism and environment.

\section{Connections}

There are many similarities between a theory of embodied perception and other contemporary approaches to actor training, particularly the movementbased and psychophysical approaches of Grotowski, Barba, or Chaikin. For example, like Barba and Grotowski I am interested in techniques that help actors to discover and break with their daily or habitual movement patterns-the concept 
of training as a removal of blocks, or a via negativa. However, Barba's intention overall is to understand, even naturalize and universalize notions of the actor's presence through his theatre anthropology (Hodge 7). By "presence," Barba means an ineffable power by which a given performer (particularly an Asian performer) is able to command or attract audience attention. Barba has explored this notion of presence through exercises meant to remove the actor's daily movement patterns, and work with the actor's use of energy (Watson 210). And whereas Grotowski's psychophysical training is not meant to be used to develop a particular role for performance (Wolford 198), embodied perceptual practices are meant to be used as such. Finally, Koltai also makes comparisons between Authentic Movement and Peter Brook's ideas of the "flowing static" and "transparency" ("Authentic Movement" 22-24). One of the primary differences between embodied perceptual practices and similar approaches rests on the topic of the so-called presence of the actor and its reinscription of the mind/ body problem. Presence is a complicated term whose definition ranges from Adler's notion of a sort of attention in the moment to a problematic bodily depth, and Barba's almost mystical definition of an attractive energy possessed by some performers, to more subtle theories, such as Grotowski's privileging of the actor's "impulse." For example, Grotowski describes an attempt to "eliminate the organism's resistance to the psychic process. The result is freedom from the time-lapse between inner impulse and outer reaction in such a way that the impulse is already an outer reaction . . . the body vanishes, burns, and the spectator sees only a series of visible [psychic] impulses" (Grotowski 16). This description reinscribes an antagonistic (or resistant) split between the organism and its so-called psychic process. However, embodied perceptual practices, articulated through Damasio's model of mind, conceive of psychic process (or the process called mind) as the result of the interaction of an "indissociable organism" with/in its environment, not a result of it being at odds with a physical presence. What's more, for Grotowski, the body is primarily a tool to reveal the mind or soul of the actor, to be erased or burned in order to reveal a distilled essence. As Philip Auslander has noted, "Grotowski privileges the self over the role in that the role is primarily a tool for self-exposure" (qtd. in Wolford 197). This kind of self-exposure, revealing an essential distillation, is reliant upon the mind/body split, which we've noted is part and parcel of the metaphysics of presence. Instead, the provisional or revised notion of presence that I am arguing for here is based on a polyphonic layering of attention to perceptual and recalled imagery.

\section{Practicing Practice: Wallace Shawn's The Fever}

Embodied perceptual practices constituted the main approach to the rehearsal process for two recent productions of Wallace Shawn's play, The Fever (1991), a sixty-eight-page monologue that is brilliantly poetic while intelligently critical of the culture of privilege. The first production (December 3-5, 2003) was the actor's MFA thesis performance at the University of California, Davis; the second (February 2004) was performed at a private home in Yakima, Washington, for a local women's reading group. Both were performed by Sharon Porter McAllister, and although they shared the same rehearsal process they were strikingly different, attesting in part to the versatility of a creative process that uses embodied perceptual practices. 
The nameless character in Shawn's play is of unspecified age, gender, race, and ethnicity; the author suggests that the piece be performed in homes or apartments by a "wide range of performers-women, men-older, younger" (69). The only possible identification is that the character speaks from a position of class privilege.

The text itself is structured like a montage, sequencing and overlapping multiple locations in space and time. In paragraph after paragraph, the character, consumed by fever, shifts between giving a first-person present-tense description of a hotel in a revolutionary country, where she is sick on the bathroom floor, to other present-tense descriptions of torture, including her own. The text also includes narratives of various memories from her comfortable lifestyle-some told in the present tense, others in reminiscence. For example, in one paragraph the character declares, ". . . I'm sitting, shivering, on the bathroom floor, this cold square of tile on a hot night in a hot country, and I can't stand up to go back to bed ..." and in the very next paragraph states, "It's the birthday party in the fancy restaurant. Yes-there's the table with its sweet and pretty decorations ..." (5). It is both a challenging and an intriguing text to stage.

Metaphorically, the character's fever represents an eruption of her worldview as she attempts to reconcile her privilege with an emerging class-consciousness. All the while she needs to hold onto the idea that "life is a gift" (11). The gift is one of the primary metaphors in the text, from a long description of unwrapping presents (11-14) to numerous other references sprinkled liberally every few pages. The image of the gift is set in high relief against the beauty and incredible violence of the play; in this sense, the gift, like privilege, becomes a burden for the character.

Shawn initially performed this piece for private audiences in the living rooms of New York's elite, while seated in a chair plainly reciting the text. The audience would be seated facing him, perhaps enjoying something to eat or drink. Our first production of The Fever staged a somewhat ironic quotation of these original performances, inviting our audience members to participate in a "gift raffle" to win one of three onstage seats as the actor's guest. The actor presented her onstage audience with gifts and party favors, and served them jasmine tea, sparkling cider, and tiramisu during sections of the performance (figure 1). By turning the original relationship between Shawn and his private audience to the "side" for viewing by a larger audience, we exposed various power relations that are drawn out in the play. For example, at one point the onstage audience was eating their tiramisu - a rich sponge cake soaked in coffee and marsala-while the actor described a female guard, a torturer, "whose face is like a cake that's been soaked in rage" (42). Even the actor's simple gesture of serving food to the onstage guests shifted between the flourish of a hostess and the economical action of a maid-another image that frequents the text.

The metaphor of the gift as a burden, and the ironic staging with audience interaction, were the main concepts by which I directed our overall approach to the production. The set design juxtaposed a living-room scene stage right with a more open space stage left, which was used to occasionally project video imagery representing and amplifying the character's hallucinatory condition, and also in order to connote the multiple settings layered into the richness of Shawn's text. Other than occasional projection, this more open space contained only the 


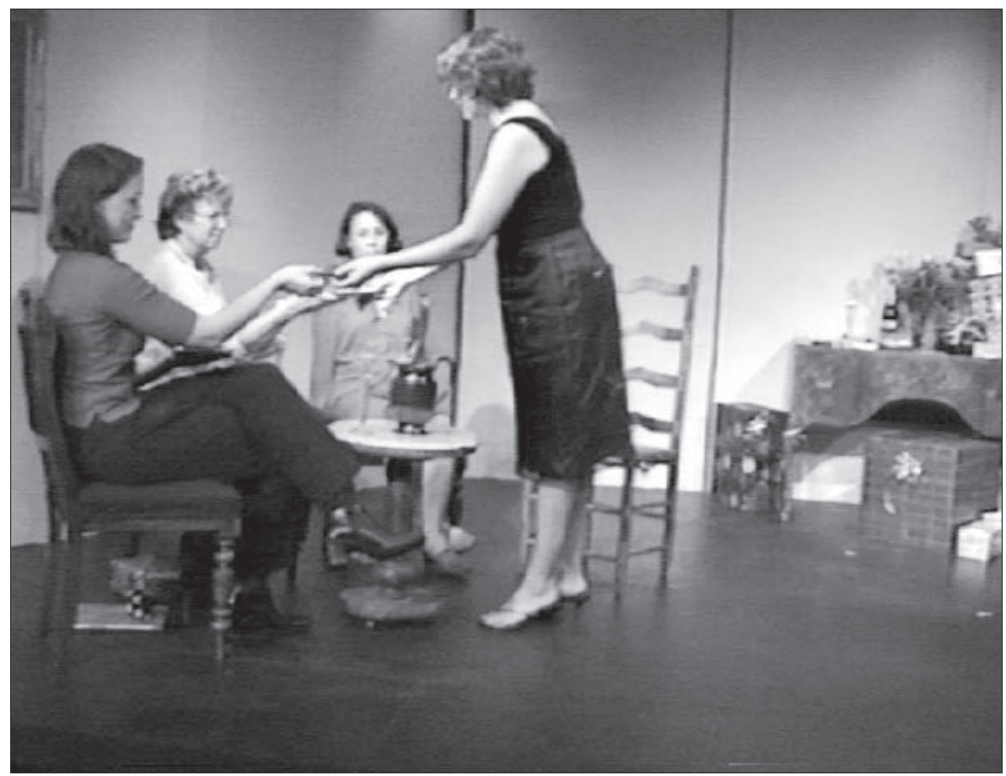

FIG. 1. "It's the birthday party in the fancy restaurant. Yes-there's the table with its sweet and pretty decorations, the fanciful centerpiece, pink and green, and there are all the women in bright red lipstick and the men in beautiful shirts, and all the gifts-outrageous, unexpected, and funny gifts-and there are the waiters serving the salmon and pouring the wine, and there I am" (Shawn 5). Video image by Jeremy Vaughan.

character's suitcase and a worn rattan chair. Centered at the back of the stage was the sideboard with its tea service, cakes, and excess of gifts.

Our concept for staging this play presented various challenges to the actor. In this case, she needed to develop: 1) improvisational skills for interacting with the onstage audience, and 2) an approach to the role that would not rely on traditional notions of character motivation-i.e., actions and objectives, or personal connection and emotional response to images of torture, etc. In other words, given the play's nonlinear structure, as well as the conceptual approach to the production, a literal or realist staging of the text would likely produce sheer melodrama or dull its critical edge. At a practical level, I needed to help the actor find a way to accomplish several tasks. First and foremost was to source the character through embodied perceptual practices, because it was through this process that the other tasks were largely achieved. As such, embodied perceptual practices helped the actor to memorize an enormous amount of text; develop improvisation skills; block out a nonrealistic production (or determine generally where she needed to be on stage at different points in the text without the necessity of narrative plot as a guide); and move beyond her technical limitations in preparing for the role. This same process was also used, in dialogue with the directing concept, to develop a score for use in performance.

Thus, with the directing concept as a guide or general structure, the first major step in our rehearsal process was to explore the text using embodied perceptual practices, then to bring the actor's discoveries into dialogue with the production concept, and vice versa. 


\section{The Summer Workshop: An Introduction to AM and Butoh}

In order to use AM and Butoh, reframed as embodied perceptual practices, I introduced the actor to the necessary theory of embodied perception by giving her a list of the following:

1. The mind is not just the brain, but comprises brain, body, and environment in an ongoing dialogue, or thought process, that is already coded as image.

2. An image as not merely something (a picture) held in the mind but is embodied, fully sensual, including smells, sounds, etc.

3. There are two kinds of images, recalled and perceptual; and there are three types of perceptual information (proprioceptive, interoceptive, and exteroceptive).

4. A somatic marker is a kind of shorthand way to describe a process by which recalled imagery and perceptual imagery become connected, or marked by a feeling about the body (like "a gut feeling").

5. The basic concepts of dialogue are attention, or listening, and response-rather than expression. This is important because it keeps the actor from a more solipsistic, or purely self-expressive, movement practice.

The goal of the nine-day summer workshop was to discuss these concepts, read through and discuss the text, and introduce the actor to the basics of Authentic Movement and Butoh. These were necessary steps before we could begin using AM and Butoh to explore the text directly.

In the mornings we read and discussed a section of the script or talked about the theory, and after a break would work with AM and/or Butoh. A typical AM session consisted of approximately twenty minutes of movement. The actor would begin in any position (sitting, standing, lying down), and with her eyes closed could move in any way she chose. Initially the actor does not work with memorized text while moving; therefore, the movement can seem quite random. However, it is not quite the case that the actor moves randomly until something happens, but rather that as soon as she is moving (no matter how imperceptible that movement may seem to the witness) something $i s$ happening, and the actor is learning to become aware of it. ${ }^{10}$ The actor's goal is simply to pay attention to what is happening by bringing attention to the three kinds of perceptual imagery and noting any recalled imagery as it occurs; she chooses to respond to movement impulses, or to let them go. For example, she might bring her attention to her breath or heartbeat (introception), her muscles and the articulation of her skeleton (proprioception), and to the space around her (through hearing and other exteroceptive perception), then notice any recalled images (visual, aural, olfactory, textural) as they emerge. At the end of the movement period, we talked about the process and the actor attempted to track her movements, images, and sensations as closely as possible in both speaking and writing.

It is also important to note that the practice of Authentic Movement requires that the actor not only move, but witness others moving; experiencing the witness role is essential to the use of embodied perceptual practices because it helps 
the actor to increase her ability to bring attention to her own movement as it unfolds, rather than getting lost in self-expression. In other words, without experiencing the witness role, the mover tends to remain in a more private world (eyes closed) where one has total freedom to move in any way one chooses, falling prey to the expressivity that is problematized in point 5 above. However, in a practice of AM the mover's goal is to track, or follow, her movement experience as closely as possible-not to lose herself in it. It is not that one expresses through movement, but that one learns to listen, to attend to one's movement. Through experiencing the witness role, the mover develops a revised model of attention; through a practice of witnessing and moving the actor can become increasingly aware of the multiple layers of perceptual and recalled imagery. In this sense, the witness/mover model of AM parallels the dialogical model of mind that we have outlined above. Therefore, the stage manager and voice coach were also trained in AM and we began a weekly practice together in an open-circle form-sitting in a circle as witnesses and taking spontaneous turns as mover, with up to two people moving at once. This may be one of the hardest concepts of AM to explain without actually experiencing it, yet perhaps one of the most important in the process of using the form in rehearsal. I cannot stress enough that it is a mistake to only engage AM from the mover's perspective in actor training-so much so that we continued with this form once a week throughout our rehearsal process so that the actor could fully develop what is problematically called the "inner witness" ${ }^{11}$ in traditional AM jargon, but which I generally refer to as increased perception.

During the summer workshop, the Butoh work consisted of exploring concepts of alignment, developing and using the muscles closest to the bone through various floor exercises, and working with guided imagery. ${ }^{12}$ For example, we might spend twenty minutes on an exercise wherein the actor presses her spine firmly against the floor with knees bent and feet firmly planted. The chin is tucked slightly so that the back of the neck is long but does not restrict the throat area. From this position, the actor is instructed, by guided imagery, to begin to perceive various sensations in her body and to move from them. For example, the sensation of small branches growing in between her fingers begins to pull her arms upward away from her body. She is encouraged not to use her major muscles, and to move slowly in time with her breath so as to begin to use smaller muscles, which are closer to the bone. These exercises were important to our later process of using guided imagery to develop specific images from the text.

During the workshop we also began to notice and begin to clear any restrictive movement patterns. For example, the actor presented concerns about feeling physically boxed in and rigid in her movement-afraid to be off balance (she had just taken a year's leave in order to have a child, and had been somewhat sedentary). In response, we began some Butoh work that included pushing the body to an extreme state of imbalance: when the actor worked with the muscles closest to the bone, and slowed the speed of movement, the result was often a shaking or quivering effect. To further this exploration I had the actor read a portion of the text aloud while standing on one leg, leaning her torso forward with her dominant arm behind her back, holding the script in her other hand. She had to struggle to keep her balance and soon was short of breath. The result was very interesting-the actor was forced to stop interpreting the text as a result of needing to focus on maintaining balance, reading, and breathing. The work with small muscles and states of imbalance served not only to begin to clear the actor's 
own repetitive movement patterns, but was also used to develop a vocabulary of twitches, etc., that was later scored into sections of the performance. Finally, it should be noted that the director may choose to modify exercises according to the needs of the particular production and the working preferences of the actor.

\section{Rehearsals: Sourcing a Text with Embodied Perceptual Practices}

Once the actor worked with the basics of AM and Butoh, we rehearsed the production for ten weeks; the first several weeks we worked with the play in five smaller sections (approximately twelve to fifteen pages per section), using embodied perceptual practices as a way to explore the text. In a method similar to that described by Judith Koltai ("Authentic Movement"), the actor worked with already-memorized text while practicing AM; in other words, the actor began in the same way described above (eyes closed, attending to perceptual imagery), and when she felt ready, would begin speaking the memorized text (a type of recalled image). The actor's goal was to move in any way she chose while she tracked-to the best of her ability-perceptual and recalled images as well as any feelings that were triggered as she spoke the text. We went through each section two or three times in this basic way, first giving the actor total freedom to move in any way in order to discover imagery, and then each successive time with additional constraints or limitations in order to bring her work into increasing dialogue with the directing concept.

The actor made notes immediately after moving through each section of text in these ways. The notes attempted to track her experience as closely as possible. We would try to collect specific information for what the actor or I felt were more powerful moments that had occurred during the work. Specifically, we would determine what piece of text was being spoken at the time, what the actor's perceptual imagery had been in that moment (trying to be sure to gather at least one piece of information from each of the three sources), what recalled images had occurred or were used in that moment, as well as any associated body-states or feelings. We might identify between five and twenty such moments in one run-through. We archived these key moments, which we referred to as "somatic markers," in a simple chart.

A single somatic marker included data for one key moment in rehearsal (table 1). The left-hand column of the chart showed the line of text, and the other three columns showed the associated recalled images, perceptual images, and feelings. In this example, the somatic marker information documents a moment in rehearsal when the actor was speaking the following lines: "About a year ago I spent a day at a nude beach with a group of people I didn't know that well. Lying out there, naked, in the sun, there was a man who kept talking about 'the ruling class,' 'the elite,' 'the rich.' All day long” (Shawn 18). The recalled image used in the moment (in addition to the text) was a fully sensual image of "laying naked in the sun." The perceptual information indicated that she felt "sprawled out" (this would be the sense of her exteroceptive perception or location in space, as well as her proprioceptive information from muscles and bones), and that her breath was in her pelvis (interoceptive information). These recalled and perceptual images were "marked" in Damasio's terms, by the feelings of "being sprawled out" and "a little naughty." 
TABLE 1.

\begin{tabular}{l|l|l|c}
\hline \multicolumn{1}{c}{$9 / 23 / 03$} \\
\hline \multicolumn{1}{c|}{ Text } & $\begin{array}{c}\text { Recalled } \\
\text { Imagery }\end{array}$ & $\begin{array}{l}\text { Perceptual } \\
\text { Imagery }\end{array}$ & Feelings \\
\hline $\begin{array}{l}\text { ". . a a nude } \\
\text { beach ..." }\end{array}$ & laying naked in the sun & $\begin{array}{l}\text { sprawled out, breath } \\
\text { in pelvis }\end{array}$ & a little naughty \\
\hline
\end{tabular}

The shorthand used in the chart became a way to store the details of compelling moments in rehearsal. For example, this particular image-being sprawled out on the beach-remained in the final production in a modified manner, and is an example of how the imagery used in staging the production was already linked to the actor's organism during rehearsal. As the actor noted in a personal communication, "the[se] somatic markers, although anchored in the text, have been defined by the visceral experience of the actor." With the collection of this information we began to archive the bones for a very loose "score" of images, positions, gestures, movements, visceral states, breath patterns, and text based on the multiple connotations that accrued during the rehearsal process.

After a section of text had been explored with AM, Butoh work was often used to further develop particular images. For example, we used Butoh to explore the water bug, an image repeated several times in the script, which becomes a metaphor for the character:

. . in the corner of the bathroom-brown against the tile-there's an
insect, big, like a water bug-it's flat, heavy-very tough legs, they look
like metal-and it's waiting, squatting, deciding which way to move.-And
in a second it's crossed behind the sink, and it's slipping itself into a hole
too small for it to fit in, but it fits-in-it fits-it's gone. And I see myself. I
see myself. A moment of insight. (5)

Using our modified Butoh process to work on this image, the actor began by focusing her attention on the recalled image of the water bug, then gradually brought her attention to the three sources of perceptual imagery as she began to move. By suggesting that she begin with a fully sensual (recalled) image of the water bug and then bring attention to her breath, etc. (perceptual imagery), we were able to avoid the language of metamorphosis in this process. The result of this exploration was a series of squatting, sliding, and lurching movements where the actor achieved a kind of broad flattened back and fingers and wrists like antennae. But what's more significant perhaps is the way this information remained in the actor's bodymind; although we did not use this bug-like movement at this exact point in the script, two things came out of this exercise. First, this movement was incorporated successfully into a later part of the script where the actor is describing torture; second, perhaps most significantly, the movement which ultimately did occur with these lines in the text was imbued with the memory of this exploration: the actor slid herself into a shiny brown party dress, holding in her stomach as she zipped the back with the same kind of antennae-like fingers. 
Finally, additional constraints were added in order to further develop imagery in increasing dialogue with the directing concept. These included our Butoh-inspired guided imagery technique with its increasing vocabulary of twitches, imbalance, and compression, as well as more pedestrian activities, such as gift-wrapping, serving tea, etc., which were meant to develop skills necessary for the performance as well as the character. For example, I might instruct the actor to source a section of memorized text primarily using AM, with the added constraint that at various points she would need to make the clear choice to open her eyes and wrap gifts, or that at specific points the actor should explore being off balance. The activity of gift-wrapping served various purposes; we needed approximately sixty wrapped gifts for our set design, and I wanted the actor to be able to improvise with them during rehearsal in order to make discoveries for use in production (figure 2). Further, because we knew that there would be an onstage audience, people began to sit on stage during the rehearsals; food was brought and served by the actor while rehearsing certain sections of the play, so that this vocabulary of movement and interactions would not be seen as separate from the "authentic" movement. While continuing to work with AM the actor would increasingly become aware of the exteroceptive field-stage space and various people, items, etc. This meant that increasingly, the actor would work with her eyes open during a second or third run-through of a section of text.

Thus, our process of using embodied perceptual practices to explore a text in rehearsal consisted of two phases of sourcing: image discovery and image development, which were followed by the addition of limitations and constraints. In our rehearsal process we primarily used AM to discover imagery through the text, and used various Butoh guided imagery exercises to work directly with chosen images. First, the actor worked through sections of memorized text while practicing Authentic Movement. Second, after a section of text had been explored with AM, Butoh work was often used to further explore imagery from the text. After the actor had gone through the text multiple times using AM and developed key images with various Butoh techniques, additional constraints were added by the director to begin to bring the actor's work into increasing dialogue with the production concept: the ironic staging with the onstage audience, and the metaphor that the gift is ultimately a burden.

\section{Rehearsals: Scoring}

The final four weeks of our rehearsal process we began sequencing or scoring the performance, exploring our archive of somatic markers, and working increasingly with constraints to bring the material developed in rehearsal into increasing dialogue with the directing concept. As such, I began to use the information from the somatic marker archive to sequence images and moments in the text together. I also knew that there were certain activities that I wanted to occur at certain moments in the text; for example, when the character described the birthday party she needed to be serving the onstage guests their first bit of tea and cookies, sitting down with them conversationally as if they were at a party. We used a combination of this kind of structural work with the text, imagery from the archive, as well as other actions that we explored in rehearsal such as working with the gifts, interacting with the onstage audience, etc., in order to structure the performance. Ultimately we worked through several 


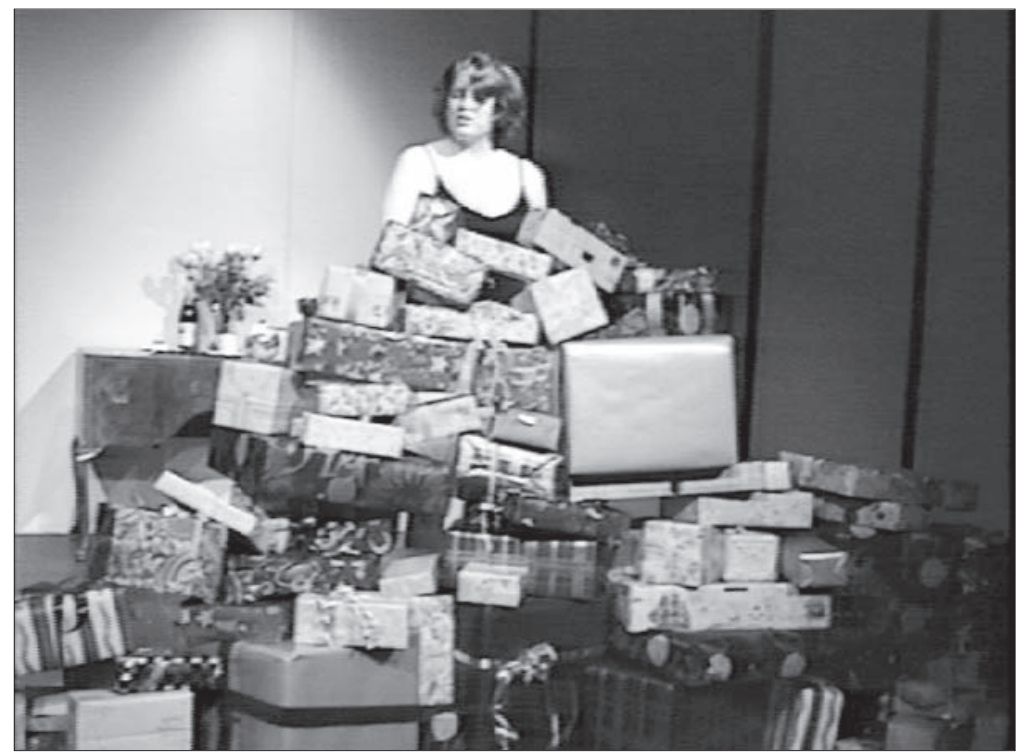

FIG. 2. The actor stands behind the wall of gifts that she has just built: "We have what we need-our position well defended from every side. Now, finally, everything can be frozen, just as it is . . From this moment, an eternal silence, the rule of law" (Shawn 49). Video image by Jeremy Vaughan.

different versions in our rehearsal process, all the while continuing to explore difficult sections with AM and Butoh as needed and maintaining our weekly AM open circle.

The sequencing, or score, on the other hand was not meant to be reproduced in any strict sense, or to inhibit the actor from a fairly improvisational performance. We tried to create a structure that allowed the actor to be able to respond in the moment (especially with the onstage audience) but which would also guide the actor as a roadmap. For example, although we knew that during the dinner party description (5-8) the actor would be serving the onstage guests, drinking tea, and telling the story of the birthday party, we did not have exact blocking (first you pour tea, then you give them napkins, etc.). This is primarily because set blocking could never account for the actions of, or interactions with, the onstage audience. During that section, the actor had to layer an improvised interaction with the guests as she asked, "Do you want tea?" even as she continued with the script. She was able to use the archived imagery, which seemed to exist not only on paper, but also in the actor's organism; it was as if she had every somatic marker "memorized." The actor was able to juggle these multiple tasks, responding to the onstage audience's unscripted presence, while maintaining attention to her perceptual imagery, the recalled imagery of the script, and any associations or connotations accrued in rehearsal or occurring in the moment (figure 3).

We also drew on the vocabulary of movement that developed in the Butoh and AM work-using the twitching movements in order to highlight particular points in the text where the character seemed particularly distraught or in a crisis of worldview (figure 4). This vocabulary also remained open to the actor at any point in performance. So, for example, on the second night of the production, she spontaneously used a particular rat-like movement (on its back, moving its claws in the air) at one moment in the text. This movement had been 


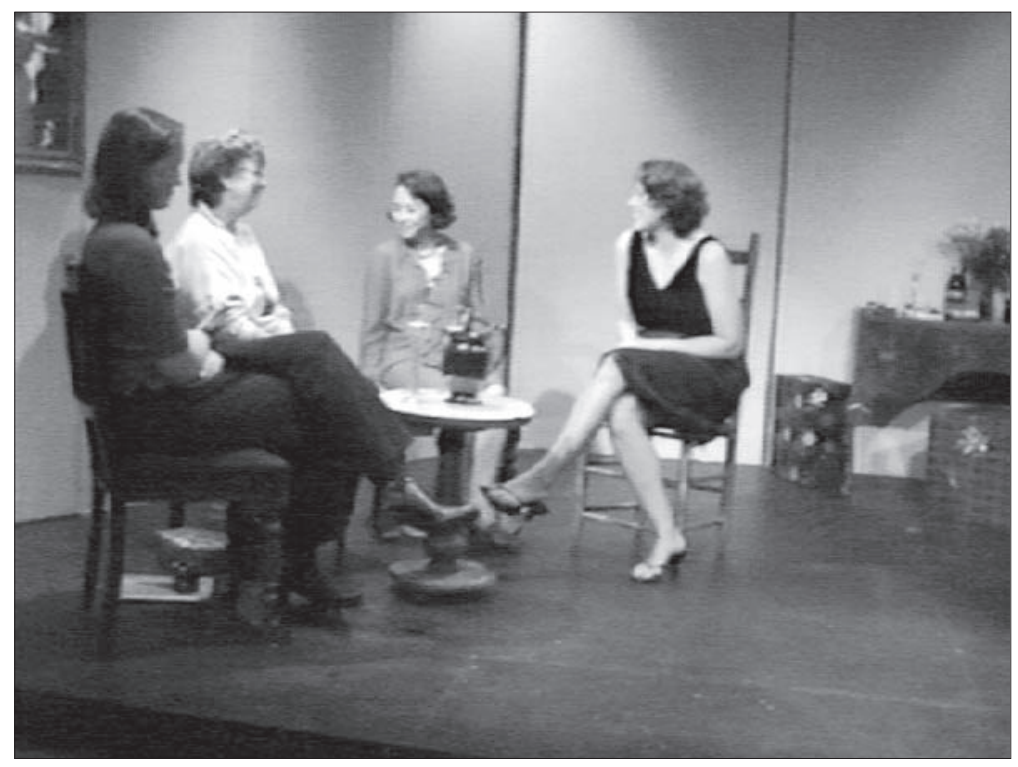

FIG. 3. "You see I like Beethoven. . . I like to follow the phrase of the violin as it goes on and on, like a deep-rooted orgasm squeezed out into a rope of sound" (Shawn 10). Video image by Jeremy Vaughan.

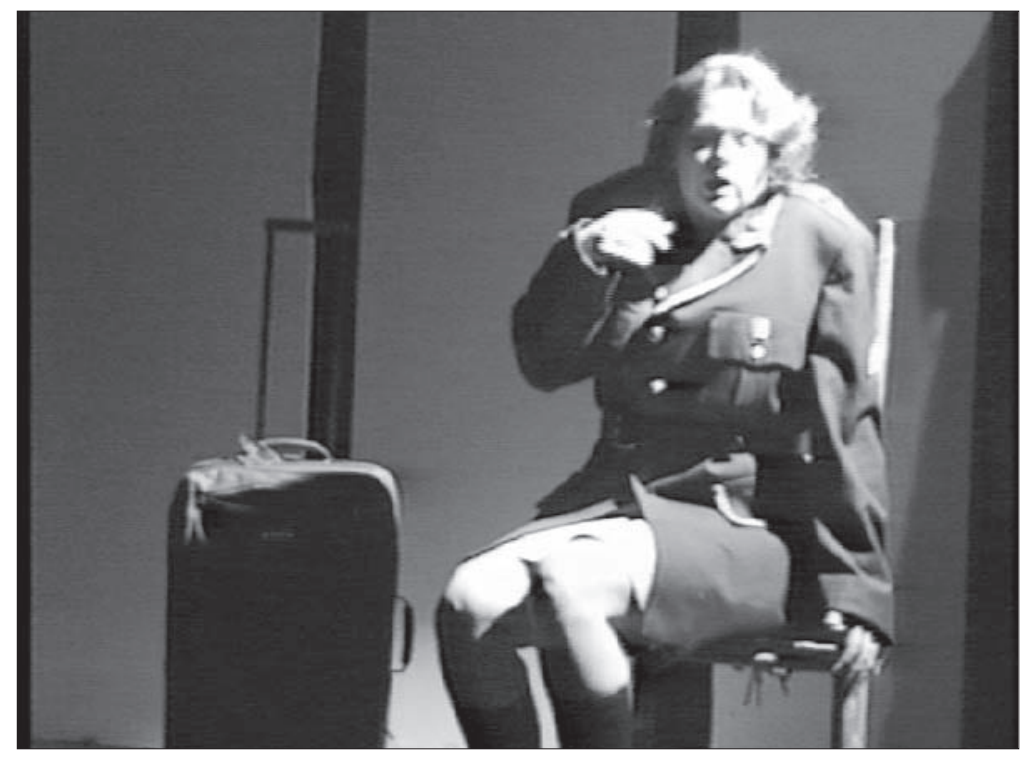

FIG. 4. "One of the guards holds my arms behind my back, the other one starts hitting me in the face with his fists. . . No one in my life has ever hit me before. I'm thinking about the damage each blow might do" (Shawn 42). Video image by Jeremy Vaughan. 
discovered while working with the text and AM during rehearsal; it reemerged in performance although we had not scored it into the final production. I encouraged the actor to remain open to these kinds of choices during performance. The strange image of the rat, used intuitively with the text "Sure, sometimes you think about the suffering of the poor-Lying in your bed, you feel a sympathy, you whisper into your pillow some words of hope: Soon you will all have medicine for your children, soon, a home" (56), was quite compelling.

\section{Production Two: Making a Blood-Orange-Glazed Pound Cake in Yakima}

Yes, suppose that certain people-certain people whose hearts admittedly are filled with love-are being awakened suddenly at night by groups of armed men. Suppose that they are being dragged into a stinking van with carpet on the floor and stomped by boots until their lips are swollen like oranges, streaming with blood. Yes, I was alive when those things were done...

-Wallace Shawn, The Fever 10

In February 2004, we restaged The Fever, in a manner consistent with Shawn's original productions, for a private reading group in Yakima, Washington, that is facilitated by a retired literature professor. The performance was given in one of the member's home for an audience of about thirty, which included the reading group members and their guests. The comfortable interior paralleled the living rooms where Shawn originally performed the work; however, rather than sitting in a chair and presenting a didactic against privilege as Shawn had done, the actor and I again wanted an ironic staging that would heighten the audience's complicity in the production and draw on the complexity of the text. The only caveat was that we would not have a chance to see the space, much less block the performance in any sense; we would not be able to use the video projection, nor would we have the huge pile of gifts which was so central to the Davis production.

There were several other factors that needed to be taken into account in order to translate the piece for this new context. For example, the actor did not feel comfortable in the primary role of hostess, given that the event would occur at someone else's home, and I agreed this concept no longer made sense. We discussed the idea of a kind of Tupperware ${ }^{\circledR}$ party, where one's product is The Fever. . . a kind of delicious presentation in privilege, consumption, and guilt. The actor began to link the character to an image of Martha Stewart, particularly on her television show, where she demonstrates making little cakes, etc., while talking about the good life and its celebrations. There certainly were ironic parallels with Shawn's script, right down to his indictment of capitalist privilege.

In Yakima, our critical strategy was to set Shawn's narrative in high relief against the actor's activity of frosting a blood-orange-glazed pound cake in a demonstrative, or how-to, manner. The large pile of gifts was replaced with tables filled with petits fours and hors d'oeuvres, which had been hand-made by the actor before the performance as part of her approach to "get into character." 13 The actor interacted with audience members in all of the same 
sections or scenes, used the twitching at the same moments of crisis in the text, and kept the "rat" movements that had been improvised in the Davis performance. Towards the end of the performance, the actor cut the cake she had glazed, and everyone ate it so that the end of the performance blurred completely into the social event that followed.

The actor needed, and was able, to improvise on the previous production. For example, instead of standing on top of one of the large gift-boxes as she had done at one point in Davis, the actor improvised by standing on a stone ledge in front of the fireplace; instead of interacting with only three confidantes, she had many who were seated throughout the L-shaped living room; instead of serving tiramisu she glazed the cake. In a personal communication, the actor commented that the sixty-eight pages had stayed with her as a "physical memory." She noted, "even though the [new] staging of the play had been completely altered, I was able to call upon the somatic markers that we had developed throughout the course of earlier rehearsals to guide me to the next moment . . . I can improvise in ways that would have scared the hell out of me in the past."

\section{Assessment/Conclusion}

In the first part of this essay I made various claims about embodied perceptual practices and their use in rehearsal and production. I'd like to look at a few of these claims in order to explore the successes and limitations of this analysis. First, I argued that embodied perceptual practices provide a way to talk about imagery and perception in rehearsal without unnecessarily reinscribing the mind/body split and its metaphysics of presence. This, I think, is one of the clear strengths of this approach, and I suggest that this way of talking about imagery can be applied broadly in actor training, even outside of the particular application of AM and Butoh.

Second, I suggested that the dialogical processes of Butoh and AM, rearticulated as embodied perceptual processes, would allow us to rethink working with imagery and movement in actor training. Certainly, I am not the first to use Authentic Movement or Butoh in actor training: AM has been used as a means to source original performance work for some time (Olsen; Josa-Jones; Fanger); and both $\mathrm{AM}$ and Butoh have become increasingly popular in actor training (Pippin; Koltai). Each has been institutionalized, at least to some degree, in actor training programs in Canada, the UK, and the US. ${ }^{14}$ Despite this, there are only a handful of articles that are concerned with AM and the creation of performance work, and none of these has analyzed it in the production of scripted performance work. Similarly, much has been written about Butoh dance-its training and form-from the initial writings of Hijikata to essays, performance reviews, historiography, etc. But nothing describes its use in the production of a theatrical performance based on a dramatic text. In this sense I have not so much offered a single proof, or a case study, of some completely new approach to actor training so much as a rather overdue example of the possibilities of using these methods in production-with the advantage of being articulated within a new model.

I am also aware of certain limitations to my claim here as I only offer the example of a monologue; one wonders how this method would work with a larger cast or on a different kind of production. Although I do not offer such an 
example, others, like Sarah Hickler, have been using AM over the last several years to work with acting students in order not only to develop character, but also to strengthen ensemble work. ${ }^{15}$ This suggests that this process is already useful in different kinds of productions, although Hickler has not yet documented her process and its success or effects. It is my hope that more work will be done to not only further test the use of $\mathrm{AM}$ and Butoh in actor training and in production, but more specifically, that others will attempt to use the general theory of embodied perceptual practices in order to test it on a variety of productions.

Third, I suggested that embodied perceptual practices would offer successful methods for sourcing character and working with script; I believe this claim holds. Judith Koltai too has used AM to work with memorized script, and attests to its usefulness, although she has not offered a specific analysis of her process. Sharon Porter McAllister, the actor in the project, considers our process to be particularly useful in this way; after the Yakima production she stated, "One of most valuable things [about this approach] has been the introduction of text: to discover the meaning of the words I speak as they pass through me; to discover the same words taking on new meaning as they pass through subsequent times." 16

We certainly made new discoveries during our process: working with the text and embodied perceptual practices turned out to be an excellent mnemonic device-the material was memorized experientially and was not easily forgotten; and theatre made by means of embodied perceptual processes has the potential to be incredibly flexible. As the actor noted, "it seems meant to travel . . part of its strength lies in the adaptability it creates," although this too remains to be tested in other contexts and with other productions.

Embodied perceptual practices not only produced multilayered imagery, but also helped the actor to achieve a state of what might be called perceptual polyphony, the ability to work simultaneously with text, perceptual and recalled imagery, and associated feelings. Through this sort of articulated practice, the performer increased her ability to hold multiple awarenesses, and has incorporated a flexible language to articulate perceptual states and processes. The actor has become more able to "adjust [her] brain/body through breath and imagery to respond to the tasks at hand" (Sellers-Young 96): able to respond to impulse (imagery, information) from various receptors, allowing for a spontaneous and powerful performance.

Finally, one might also ask if these productions have been successful from the point of view of Shawn's content, or whether we can be accused of creating an easily consumed product for the bourgeois class. On the contrary, although we have served it with tiramisu and petits fours, the piece remains difficult to swallow. After one of the evenings of the first production, an onstage audience member said, "I felt so complicit." To me, this was a sign of our success-we never intended for the audience to feel accused, but to feel precisely complicit, aware of their own participation in the events and dynamics described by Shawn. I think this was particularly clear as the onstage audience sat with their champagne flutes, party favors, gifts, and tiramisu. At the Yakima performance this was manifest in the glazed cake and its consumption by the audience: "But no. No. I see it so clearly. I see myself with my little fork-I wasn't a person who was thinking about a party. I was a person who was at a party, who sat at the table, drank the wine..." (Shawn 6) ... and ate the cake. 
Shannon Rose Riley, MFA, has performed and exhibited in Europe and the US, most recently at Mobius-25, Boston (2003). From 1998 to 2002, she taught performance art, critical theory, and contemporary art history at Maine College of Art, and has been a visiting artist/lecturer at the School of the Art Institute of Chicago, the School of the Museum of Fine Arts, Boston, the University of Florida, Gainesville, and other institutions. She is currently a PhD student in Performance Studies at the University of California, Davis.

\section{Notes}

Special thanks to Sharon Porter McAllister, Mike Ortiz, Jon D. Rossini, Barbara SellersYoung, Sondra Fraleigh, Jeremy Vaughan, and my anonymous readers. This work is dedicated to my mother, LaVaughn B. Riley.

1. According to the $O E D$, positivism is the name given to the view "that every rationally justifiable assertion can be scientifically verified or is capable of logical or mathematical proof."

2. Published in English as The Paradox of Acting in 1883.

3. I authored and taught the first performance classes at Maine College of Art in Portland, and have facilitated workshops and lectured at other institutions.

4. Virtuosity is one of the tropes of presence (along with notions of genius, essence, etc.) that fall under scrutiny within postmodern criticism because it is a discourse that privileges the modernist subject and its mind/body dualism. In this context I suggest that Butoh also makes recourse to such a rhetoric in order to describe its processes and effects. Other more theoretical criticisms of virtuosity as an effect of modernist specialization lie outside the scope of this paper.

5. Barbara Sellers-Young has also used Damasio's notion of the body-minded brain as part of her theory of actor training, which is based on the ideas of feel, fuse, and follow.

6. I do not want to suggest that there is some original, purely biological, or essential self underneath these cultural and personal embodied patterns. We do not use clearing to find the actor's "true body" or some similar concept, only to learn to attend to the various patterns that are the result of socialization and the daily performance of the self.

7. The witness is allowed to infrequently call out "freeze," etc., at any point that movers need to softly open their eyes, check their position, readjust, and continue, but this should be used sparingly.

8. After studying with Mary Wigman in Germany, Takaya Eguchi and Soko Miya founded a school in Tokyo based to some degree on her techniques; their students included Ohno and Hijikata (Franklin 20). Others (Blackwood; Klein; Fraleigh) have noted the connection between Wigman and Butoh at more length. Mary Whitehouse, who started Authentic Movement, also had a diploma in dance from the Mary Wigman Schule in Dresden. She noted, "The Wigman training prepared me for a particular approach . . . It made room for improvisation, placing value on the creativity of the people moving" (74). 
9. My interest in Butoh is increasingly centered on its use of visualization and guided imagery to create improvisational work. I am especially interested in movements such as twitching, shaking, and working off balance, which often result with certain kinds of alignment and when using the muscles closest to the bone.

10. A desire to be able to know, or ascertain, that something is happening when it is not obvious to the witness should not lead the witness to assume that nothing is, in fact, happening. At a later point in the process of using AM for actor training and rehearsal, it becomes appropriate for the primary witness, or director, to shift to a more critical role, but when first learning the form, or initially sourcing the text in rehearsal, the director/witness should also maintain a nonjudgmental position and allow the actor to explore whatever occurs.

11. According to Janet Adler, the development of the "inner witness" is the ultimate goal for both the witness and the mover in the practice of Authentic Movement, although this language persists in employing the kind of inner/outer dichotomy that we are trying to avoid.

12. Throughout this essay I speak of guided imagery or guided visualization. By these I mean a generalized process wherein one person moves, meditates, visualizes, etc., while another guides him/her with some kind of narrative.

13. In addition to making the refreshments, the actor used about fifteen minutes of AM before the performance in order to prepare.

14. Judith Koltai (University of British Columbia) has explored Authentic Movement, voice and text work with acting students for over ten years; Florence MacGregor (Humber College; Summer Shakespeare Intensive, Toronto) is trained in AM, Chi Kung, Laban, and Alexander; Jill Margaret Pribyl (Eastern New Mexico University ) explores AM practices in the development of contemporary African choreography; and Keren Abrams uses AM in an acting lab course at Naropa Institute. Sarah Hickler (Emerson College; Shakespeare \& Co., Lenox, MA) introduces Butoh in all of her movement classes with actors, focusing on working with imagery, and uses AM in her upper-level movement classes to source material for scene and character work. Frances Barbe (University of Kent at Canterbury; University of Exeter School of Performance Arts) uses Suzuki and Butoh to rethink Western theatrical approaches.

15. Hickler's use of Butoh also centers primarily on the exploration of imagery for performance. She has used AM to develop ensemble work and choreography as the movement director/choreographer for various collaborations with director Lisa Wolpe and the Los Angeles Women's Shakespeare Company: The Tempest (2003); Twelfth Night (2001); Much Ado About Nothing (2000), etc.

16. From a personal correspondence. 


\section{Works Cited}

Adler, Gerhard. Studies in Analytical Psychology. London: Routledge and Kegan Paul, 1948.

Adler, Janet. Offering from the Conscious Body: The Discipline of Authentic Movement. Rochester, VT: Inner Traditions, 2002.

—. "Who Is the Witness: A Description of Authentic Movement." Authentic Movement: Essays by Mary Starks Whitehouse, Janet Adler and Joan Chodorow. Ed. Patrizia Pallaro. London and Philadelphia: Jessica Kingsley Publishers, 1999. 141-59.

Bakhtin, M. M. Speech Genres \& Other Late Essays. Ed. Michael Holquist and Caryl Emerson. Austin: U of Texas P, 1986.

Blackwood, Michael, dir. Butoh: Body on the Edge of Crisis. Michael Blackwood Productions, 1990.

Chodorow, Joan. "The Body as Symbol: Dance/Movement in Analysis." Authentic Movement: Essays by Mary Starks Whitehouse, Janet Adler and Joan Chodorow. Ed. Patrizia Pallaro. London and Philadelphia: Jessica Kingsley Publishers, 1999. 279-300.

Damasio, Antonio. Descartes' Error: Emotion, Reason and the Human Brain. New York: HarperCollins Publishers, Inc., 1994.

- The Feeling of What Happens: Body and Emotion in the Making of Consciousness. San Diego, New York, and London: Harcourt, Inc., 1999.

Fanger, Iris. "Paula Josa-Jones: Total Theater-Total Dance." Dance Magazine 71.9 (1997): $76-78$.

Fraleigh, Sondra Horton. Dancing into Darkness: Butoh, Zen, and Japan. Pittsburgh: U of Pittsburgh P, 1999.

Franklin, Eric. Dance Imagery for Technique and Performance. Champaign, IL: Human Kinetics, 1996.

Frantz, Gilda. "An Approach to the Center." Authentic Movement: Essays by Mary Starks Whitehouse, Janet Adler and Joan Chodorow. Ed. Patrizia Pallaro. London and Philadelphia: Jessica Kingsley Publishers, 1999. 17-28.

Grotowski, Jerzy. Towards a Poor Theatre. New York: Simon and Schuster, 1968.

Hijikata, Tatsumi. "On Material II Fautrier.” TDR 44.1 (2000): 60-61.

—. "Plucking Off the Darkness of the Flesh: An Interview with Shibusawa Tatsuhiko." TDR 44.1 (2000): 49-55.

—. "To Prison." TDR 44.1 (2000): 43-48.

Hodge, Alison, ed. Twentieth Century Actor Training. New York and London: Routledge, 2000. 
Josa-Jones, Paula. "Skin: A Collaboration with Pauline Oliveros." Contact Quarterly 16.2 (Spring/Summer 1991): 16-23.

Klein, Susan Blakeley. Ankoku Buto: The Premodern and Postmodern Influence on the Dance of Utter Darkness. New York: Cornell East Asia Series, 1988/1993.

Koltai, Judith. "Authentic Movement: The Embodied Experience of the Text." Canadian Theatre Review 78 (1994): 21-5.

—. "Forms of Feeling-Frames of Mind: Authentic Movement Practice as an Actor's Process." Contact Quarterly 27.2 (Summer/Fall 2002): 47-50.

Kurihara, Nanako. "Hijikata Tatsumi: The Words of Butoh." TDR 44.1 (2000): 12-28.

Lutterbie, John. Hearing Voices: Modern Drama and the Problem of Subjectivity. Ann Arbor: U of Michigan P, 1997.

Olsen, Andrea J. "Being Seen, Being Moved: Authentic Movement and Performance." Contact Quarterly 18.1 (Winter/Spring 1993): 46-53.

Pippin, Judy. "Ranged between Heaven and Hades: Actors' Bodies in Cross-Cultural Theatre Forms." Australasian Drama Studies 32 (1998): 23-34.

Samuels, M.D., Mike, and Nancy Samuels. Seeing with the Mind's Eye: The History, Technique and Uses of Visualization. 2nd ed. New York and La Jolla: Random House and The Bookworks, 1990.

Sellers-Young, Barbara. "Technique and the Embodied Actor." Theatre Research International 24.1 (1999): 89-97.

Shawn, Wallace. The Fever. New York: The Noonday Press: Farrar, Straus and Giroux, 1991.

Watson, Ian. "Training with Eugenio Barba: Acting Principles, the Pre-Expressive, and 'Personal Temperature'." Twentieth Century Actor Training. Ed. Alison Hodge. London and New York: Routledge, 2000. 209-21.

Whitehouse, Mary Starks. "C. G. Jung and Dance Therapy: Two Major Principles." Authentic Movement: Essays by Mary Starks Whitehouse, Janet Adler and Joan Chodorow. Ed. Patrizia Pallaro. London and Philadelphia: Jessica Kingsley Publishers, 1999. 73-101.

Wolford, Lisa. "Grotowski's Vision of the Actor: The Search for Contact." Twentieth Century Actor Training. Ed. Alison Hodge. London and New York: Routledge, 2000. 191-208.

Zarrilli, Phillip. Acting (Re)Considered: Theories and Practices (Worlds of Performance). New York: Routledge, 1995. 